(C) Walter de Gruyter $\mathrm{GmbH}$ 2020. All rights reserved. Access to this work was provided by the University of Maryland, Baltimore County (UMBC)

ScholarWorks@UMBC digital repository on the Maryland Shared Open Access (MD-SOAR) platform.

Please provide feedback

Please support the ScholarWorks@UMBC repository

by emailing scholarworks-group@umbc.edu and

telling us

what having access to this work means to you and why

it's important to you. Thank you. 


\title{
Network Effects in Infrastructure Regulation: Principles and Paradoxes
}

\author{
TIMOTHY J. BRENNAN* \\ Department of Public Policy, University of Maryland Baltimore County; \\ Senior Fellow, Resources for the Future
}

\begin{abstract}
Among the many crucial issues in infrastructure regulation has been how to handle network effects. These can both cause monopoly and complicate the management of partial transitions to competition in telecommunications and electricity. The recent global financial crisis itself reflects network effects. Reviewing the variety of definitions, manifestations, and policy consequences of network effects, in sectors both traditionally regulated and outside such regulation, can promote understanding of when networks should be regulated, what about them should be regulated, who should do the regulating - and why we should intervene.
\end{abstract}

\section{Introduction}

Regulators charged with the control of market power have to deal with numerous "infrastructure challenges in the early part of the twenty-first century" (ACCC, 2009). One is the effect of the transition to a low carbon economy on "generation assets and the configuration of the transmission network," in light of climate change concerns (ACCC, 2009; Brennan, 2009). Another is how the "transition to high speed [telecommunications] networks may see the demise of the transition to the copper access network" (ACCC, 2009). Common to all is the concept of a "network." It is not only recently that technological change made networks relevant for regulatory policy and business planning in these infrastructure sectors. Earlier technological change set the stage for what may have been the most difficult challenge facing regulators in recent decades - how to manage novel interfaces between competition and monopolies in infrastructures that had been vertically integrated and regulated from initial production to end-user consumption.

These interface challenges will be discussed in more detail, but examples at the outset may be useful. In US telecommunications, the initial interface management challenges

\footnotetext{
* Department of Public Policy, University of Maryland Baltimore County, 1000 Hilltop Circle, Baltimore, MD, 21250 USA. E-mail: Brennan@umbc.edu. This paper was originally presented as the keynote address to the Australia Competition and Consumer Commission (ACCC) Tenth Regulatory Conference, 30 July 2009. I thank Darryl Biggar for the invitation and extensive guidance and Katrina Huntington for arranging for me to attend. Comments from participants at the ACCC conference were very informative and helpful. I also thank Molly Macauley and Tom Spavins for sharing their insights on some of these issues. Finally, I am grateful for extensive comments from a reviewer and editor that did much to improve this paper. Responsibility for all errors of omission and commission here is mine alone.
} 
were ensuring compatibility of competitively supplied equipment with the network, followed by instituting non-discriminatory access prices paid by competitive long distance carriers to local monopolies following antitrust litigation that led to structural separation. This was followed in the late 1990s by statutory determination of whether and how new entrants in local telephone service would interconnect with incumbents and each other. In electricity, the major but not only ongoing interface challenge among federal and state regulators is to reconcile competition in generation with central planning necessary to ensure reliability across the grid.

Understanding network effects is thus crucial to addressing the role of network effects in infrastructure policy. Among the specific issues to think about are:

- When is regulatory intervention warranted?

- If so, what should be regulated? Prices? Access? Standards?

- If we regulate something, how should it be regulated? General competition law? Specific statute? Sectoral regulation?

- Most important for understanding all of these is why policy intervention might be necessary?

Even the cursory description of issues set out above suggests that there is no simple or uniform answer to these questions. Not everything called "network" entails a stetting with significant network effects, and not every setting with significant network effects gets or warrants infrastructure regulation. Whether and how policy should intervene to face challenges in infrastructure sectors requires an appreciation of the variety of roles network effects can play in various industries.

Rather, than add much to the extensive theoretical work already done and ongoing on network effects, the purpose of this discussion is to clarify how we think about them in practical terms by increasing awareness of the differences across sectors in definitions, economic effects, and policy responses. Reviewing the variety of facets of this issue should bring out the assorted contrasts and lessons one can draw from these sectors. Doing so should complement ongoing discussions within and among the business, policy, and research communities concerned with networks and regulated infrastructures.

This discussion begins with some definitions of network effects, with only a brief mention of issues that dominated the early analyses: whether individuals and markets would choose the right set of network characteristics, and whether networks should be open or proprietary. As the focus here is on infrastructure policy, we do not cover in detail aspects of network effects that may play a role in competition analyses, such as tradeoffs between standards and variety, innovation incentives, requiring backward compatibility, and the breadth of intellectual property rights. That said, to understand the wider variety of issues, it will be worthwhile to look at three areas outside the purview of economic regulators, but where networks and network effects have seen considerable attention broadcasting, standard setting, and computer software. With this background, we can explore issues in two leading sectors of interest here, first telecommunications, including traditional and mobile telephony, broadband service, and the Internet, followed by electricity.

One other network deserves mention - credit. The recent global financial crisis merits attention because it reveals that credit markets, especially for short-term loans among 
financial institutions, can be susceptible to network effects. Concluding with observations on the causes of those network effects not only provides insight into how financial institutions may be regulated in the future. It also offers yet more sides to the complex but fundamental role of network effects in infrastructure, physical and otherwise.

\section{Definitions and early debates}

\subsection{What are network effects?}

The main cause of network effects is the phenomenon known as network externalities or, sometimes, demand-side economies of scale. These arise when the value to a consumer of using a particular product increases with the number of its other users. A good example, and one to which we will briefly return, is associated with the Microsoft Windows operating system. The value of Windows arises in large measure because (almost) everyone else uses it as well. This can facilitate not only communication through file sharing, but its ubiquity also means that one can sit down at a computer almost anywhere and know what to do - an advantage made especially vivid to me when I spent two weeks in Uzbekistan in 2005. The equipment, network, and version of Windows were all old and slow, but after switching the keyboard from Cyrillic to Roman letters, I was up and running.

A second manifestation of network effects is similar and, at some abstract level, may be the same, but merits separate mention as it goes up the vertical supply chain to upstream suppliers rather than down it to end users. Just as sometimes consumers prefer to use the same item others are using, manufacturers may want to make their goods compatible with those made by others. ${ }^{1}$ From a purely strategic standpoint, one would expect the opposite, all else equal - a firm can make more money the more differentiated it is from others and, thus, the less competition it faces from them. Network effects are present largely when the gains from compatibility, not necessarily with each other but with a common standard, are pronounced in facilitating the development of complementary products.

Telecommunications provides the clearest examples. Entry by any radio, television, or mobile telephone manufacturer is promoted and likely requires knowledge of where in the spectrum radio, television, and mobile telephone transmissions will be found. The network effects in these settings span multiple sides of a market. Those providing the transmission services want to know how the receiving equipment will be configured, and consumer demand for receiving equipment requires confidence that the equipment will get the content they seek.

A third, broader context for or definition of network effects is non-pecuniary horizontal externalities. Competition creates pecuniary externalities, but those do not create or indicate a divergence from an efficient outcome that may require private coordination or public policy to address. Two relevant examples come from telecommunications and electricity. On the telecommunications side is be the shared numbering plan, which easily allows everyone to call everyone else. A less visible variation is the Internet protocol addressing system that allows computers to be identified as origins, destinations, and routing points for data packets. On the electricity side is the shared transmission grid. Because routing high voltage electricity is prohibitively expensive and electricity takes all

1 Katz, Michael and Carl Shapiro (1985) distinguish demand-side externalities and facilitating complementary markets as direct and indirect network externalities; see also Vanberg (2005). 
paths to go from one destination to another, the transmission grid becomes effectively a single network. If I expand my transmission capacity, your cost of delivering traffic is reduced. In both of these circumstances, the network externalities create interconnection issues that continue to present significant challenges to the infrastructure and its regulators.

One use of the term "network" is omitted here. In some cases, the term network is referred generically to a good or service for which the production cost exhibits significant economies of scale and geographic economies of scope but where no network effects are present. An example is water. Water is a crucial part of the infrastructure, but the existence of extensive systems for treating and delivering clean water for consumption, managing storm flow and drainage, and removing and treating waste water to protect public health and the environment, do not qualify as a network. No network demand-side or horizontal production externalities, or other compatibility issues are significant. The benefits I get from the water I use are unaffected by whether you are using the same water.

Other infrastructure industries also get the term "network" because of scale economies and geographic scope involving transportation - air and rail, in particular. There may be network effects resulting from savings from avoiding having to switch airlines to travel between two cities or ubiquitous compatibility of rail cars with track dimensions. Partly for such reasons, interconnection issues have been of interest to competition authorities, although interestingly in opposite directions. In air travel, the concern typically is excessive interconnection in the air sector that precludes potential competition, while in rail the competitive issue is insufficient interconnection in rail to exploit monopoly power over a particular route. Overall, though, network effects in these sectors may be thought of as matters of efficient scale and scope of entry rather than a demand-side or compatibility externality. Most of us would prefer that people not be trying to get on the same flight or rail car we happen to be on.

\subsection{Other debates}

Two issues, neither of which is central here, dominated early analysis of network effects. The first arose because when there are demand-side network externalities or market compatibility reasons, the parameter determining the network is often arbitrary. As those who travel know, the shape of an electrical plug, a mundane but important network effect, is largely arbitrary. So too are the voltage and cycling rates of the alternating current used to power equipment plugged into electricity outlets. Of course, as travellers learn, that very arbitrariness means that different countries adopt different standards, requiring one to use adapters to use one's equipment in other countries.

The controversy arose when one standard might be better than another. Alleged examples raised over the years have been about whether the English QWERTY typing keyboard format is inferior to those designed with letter use frequency more in mind, the VHS vs. Beta videocassette format battle, Apple vs. Microsoft in computer operating systems, and most recently Blu-Ray vs. HD-DVD high-definition videodisc players. Some of the original theoretical papers in economics addressing the compatibility aspect of network effects suggested that markets might lead to inferior standards (Farrell and Saloner, 1985; David, 1985; Katz and Shapiro, 1986). The crux of the argument is that each individual's decision to adopt or switch to particular technology depends on how much she values one technology over another, and because of network effects, what she expects others to do. If network effects are strong enough, prophecies become self- 
fulfilling - almost everyone adopts Technology A over Technology B because each expects almost everyone else to do so.

These outcomes can be realized even if most people prefer B to A, reflecting excessive inertia preventing adoption of a better standard - path-dependence (Arthur, 1994) - or excessive momentum to switch to an inferior one. In principle, public policy mandating a standard different from what the market would select could lead to an economically preferable outcome. These results engendered a contrary response, grounded largely in evidence that the allegedly inferior product the market chose was not inferior at all (Liebowitz and Margolis, 1990, 1994, 1995, 1996). According to some of these responses, the allegedly inferior VHS videotape format was the first to allow game-length recording, and studies showing the alleged superiority of alternatives to QWERTY were rigged by the alternative's developer. ${ }^{2}$

A second debate touched on indirectly here is whether a standard facilitating network effects should be open and shared with competitors or remain proprietary. Such issues reportedly continue to garner attention by competition law enforcers, e.g., whether there is something amiss in the US of Apple granting exclusive use of the iPhone to a single mobile carrier. ${ }^{3}$ A competitive analysis of exclusive dealing is not addressed here; for more, see Brennan (2007, 2008a). However, the open vs. proprietary debate is related to network interconnection policy, addressed below at more length.

\section{$3 \quad$ Network effects outside regulated sectors}

Before coming to regulatory responses to network effects in the telecom and electricity infrastructures, some useful perspective can be gained by looking at how network effects play out in less regulated or unregulated sectors.

\subsection{Broadcasting}

Providers of radio programs and later television programs that were broadcast nationwide or over a wide region have been called "networks." Although these entities involve organizing a group of broadcasters to ensure availability of the programs over a large area, the term "network" has come to be ironic, since little about what these programmers provide involves a network effect as defined above. Other than the social phenomenon of being part of a community able to share the experience of having viewed a particular news, sports, or entertainment program, there is little reason to think that one person's demand for a program increases with the number of others who view it. ${ }^{4}$ A viewer may hope for a larger audience, to generate sufficient revenues from advertiser support or audience

\footnotetext{
${ }^{2}$ Closely related to the decision on which standard to adopt is when it should be adopted, since locking into a standard inhibits adopting a more efficient standard at a later time. This is discussed at more length in note 12 infra.

${ }^{3}$ Kang, Ceclia, “Key Senator Backs Telecom Probe,” Washington Post (July 7, 2009). Without assessing the merits in full, we can note that development of the communications platform and marketing necessary to support the introduction of the iPhone could have warranted vertical quasi-integration through exclusive dealing. Moreover, presumably those benefits exceed the gains Apple would have reaped from exploiting competition among wireless carriers offering it.

${ }^{4}$ Some commentators have lamented the demise of mass audience news programs that may foster a common communal identity rather than the political and social differentiation of media that preach to targeted choirs.
} 
payment to keep the program on the air, but that does not affect the utility from having viewed the program.

Broadcast networks illustrate well the distinction between a network as a matter of scale and scope and networks driven by demand-side externalities or interests in compatibility. ${ }^{5}$ But as noted above, broadcasters are part of an industry that has relied on regulation to resolve network effects associated broadly with assigning specific uses to different parts of the electromagnetic spectrum, e.g., for radio, television, cell phones, etc. Such assignments need not rule out granting property rights over the spectrum, to treat it as if it were akin to land or other conventionally alienable resources. One can have land be alienable while still allow zoning boards to limit uses to different categories of residential, commercial, industrial, or agricultural use. As with land regulation, such designations may be inefficient; spectrum might be more valuable in one use than another. ${ }^{6}$

Property rights in spectrum are also consistent with the absence of that kind of "zoning" for particular uses. A license owner could make her spectrum available on an open basis, without use designations (Brennan, 1998). Technology may be facilitating such openings in two respects. One would be that "spread spectrum" technologies could allow devices to search across radio frequencies to find open frequencies for transmission, and receptors could similar search to find desired content. A more likely scenario is the one we already see in the wired world, in which content of any form - data, voice, or video - is being transmitted and received as homogeneous digital packets. Technical and policy challenges that remain for infrastructure regulators, among those being volume - whether there is enough spectrum out there for everyone to obtain high-definition video on demand - and latency - whether certain bit streams require priority handling to avoid lags that, while tolerable for reading email or downloading websites, is intolerable for telephone calls or watching movies.

\subsection{A short note on standards}

Considering the possibility that wireless Internet service will render spectrum use designations obsolete brings to the fore the issue of standard setting. Standard setting can ensure a wide range of industry participants by making available to all the information necessary to be compatible with everyone else's equipment. It facilitates competition in the sale of music that all music producers are able to issue music on standardized compact

\footnotetext{
${ }^{5}$ A reviewer asked whether network externality arguments apply to European Commission and Ofcom complaints regarding BSkyB's acquisition of sporting event rights. Shah, Saeed, "BSkyB faces legal challenge to football rights bid," The Independent Media (20 October 2003), available at http://www.independent.co.uk/news/media/bskyb-faces-legal-challenge-to-football-rights-bid-583994.html; "Ofcom Threatens Action Against Sky," The Political Economy of Football, 28 June 2009, available at http://www.footballeconomy.com/archive/archive_2009_jun_31.htm. With regard to EC complaints that BSkyB overpaid to obtain Premier League right, the main issue would be whether doing so foreclosed the possibility of individual teams competing to sell rights, following the model in Brennan (2008a). If the Premier League should have the ability to market TV rights collectively, this argument disappears. Ofcom's requirement that BSkyB resell rights to rivals may say something about football as an "essential facility" and scale economies in broadcasting, but it does not rely on network effects. Models speaking to that issue, akin to those in Rasmusen et. al. (1991), do not rely on network effects, although Doganoglu and Wright (2010) provide an exclusion model that does.

${ }^{6}$ Ideally, evidence on the value of spectrum, e.g., results from auctions or sales of licenses, could provide some information on spectrum value. In practice, if buyers and sellers in the spectrum market expected the government to reallocate spectrum on the basis of its value, however, the price of spectrum in auction or sales markets would reflect its value in the greater use, not the use at the time of the purchase.
} 
discs or MP3 formats. That example raises concerns mentioned above regarding exclusivity, in that the format for iTunes is proprietary to Apple, ensuring that songs purchased through iTunes cannot be played on portable music players other than Apple's iPods. ${ }^{7}$

Another competition issue is associated with industry-wide negotiated pricing of access to standards; this will be covered in addressing below the similar issue of interconnection among competing telecommunications providers. A recent issue affecting competition authorities around the globe is whether fraudulent misrepresentation of patent ownership in standards negotiations should be considered a violation of antitrust law. One of the two US antitrust agencies, the Federal Trade Commission (FTC), determined that Rambus, a maker of memory chips, was guilty of monopolization when it deceived an industry standardsetting body by not revealing that it held or was developing patents on a technology it successfully pushed to be included in the standard. ${ }^{8}$ The FTC dropped the matter after a US Court of Appeals ruled that Rambus's practice at worst allowed it to extract monopoly power it already had, but it did not create new power. ${ }^{9}$ A more central point could and should be whether deception should be handled through competition law or as a breach of contractual duties (attendant to participating in the standard-setting organization) (Froeb and Ganglmair, 2009; Wright, 2009). ${ }^{10}$

A standards issue that may fall upon regulators arises when there is little reason to prefer one standard to another. The fact that it may not matter may make it more difficult for parties or the market to arrive at a common choice, inviting regulators to make the decision. In the US, that very indifference to the outcome can paralyse the regulator. The lack of an overall reason to choose one or the other, with the only justification for intervention the need to choose something, means that those with a vested interest in choosing one standard will have cause to block the regulator, claiming that the decision meets the "arbitrary and capricious" standard for reversal under US administrative law. An example of this paradox was when the US telecommunications regulator, the Federal Communications Commission (FCC) was unable to implement a standard for stereo broadcasting on the low frequency AM radio band. ${ }^{11}$

\subsection{Microsoft}

Microsoft is not a regulated utility, but its operating systems and leading applications are as much a part of our infrastructure as telecommunications, electricity, rail and water. It

\footnotetext{
${ }^{7}$ One website recommends that to play iTunes music on a competing music player, one burn the iTunes versions to a CD and then convert the CD to a generic MP3 format compatible with the competing player.

8 FTC, "FTC Finds Rambus Unlawfully Obtained Monopoly Power," (2 Aug. 2006) available at http://www.ftc.gov/opa/2006/08/rambus.shtm.

${ }^{9}$ Rambus v. FTC, U.S. Court of Appeals for the District of Columbia (22 Apr. 2008), available at http://pacer.cadc.uscourts.gov/docs/common/opinions/200804/07-1086-1112217.pdf.

${ }^{10}$ Sidak (2009) raises concerns that standard setting organizations may have monopsony power in markets for standard-relevant technologies, with implications for innovation.

${ }^{11}$ A similar inability likely contributed to the FCC's delay in adopting a high-definition broadcast standard. That was likely fortuitous, as original proposals pre-dated the wide availability of digital televisions. Had a standard been adopted in a timely fashion, the US might have been saddled with analogue high definition television, and an even more costly and less timely transition to digital. Recognizing that leaves open the question of whether policy intervention is necessarily bad because something better will come along. The costs of reversal, however, warrant caution in settings where technological change is ongoing and rapid, akin to how real-options theory, i.e., the sacrifice of options to choose later suggests that returns on irreversible investments should cover more than the nominal cost of capital.
} 
has also surely been the subject of policy attention by antitrust enforcers qua regulators. Few companies symbolize the significant technological change facing infrastructure industries and the global economy as vividly as Microsoft. Finally, a leading cause of both Microsoft's infrastructure status and the antitrust scrutiny it has received arise from network effects in its operations. A brief look at it can provide some additional enlightenment on how technology-driven network effects challenge infrastructure sectors and those charged with their oversight.

Computer operating systems are a paradigmatic example of network externality. Any operating system if more valuable to an individual the more other individuals also use it. This facilitates not only communication between users, such as sharing files and media that can be read on multiple systems. As vividly revealed to me in Uzbekistan, wide use of a common operating system also enables people to work on different computers in different locations. Complementing this network externality on the demand side are the market scale benefits application writers derive from knowing that if they write a program that runs on Windows, it will be available to the vast majority of computer users. Combined with the cost in money and time to acquire and learn new applications on new operating systems and the (non-network) scale economies associated with the production of operating systems, ${ }^{12}$ this has been responsible for Microsoft's long-standing dominance in the operating system market.

Network effects also contributed to arguments to bring antitrust action against Microsoft. A central justification was that Web browsers, along with programs that could run applications delivered through them, could provide a platform for applications that would eat into Microsoft's future dominance of that market. ${ }^{13}$ Although network effects seemed to be core justifications for the case against Microsoft, they also subverted the economics of the case in two important ways.

One is that some leading theories of strategic entry deterrence in innovative industries rest on the asymmetry between an incumbent and entrant in the outcome if entry deterrence is or is not successful. In these models, the incumbent has more to gain by entry deterrence because it keeps a monopoly, while the entrant has to share the market if it is not deterred and thus typically gets less than half the monopoly profit. This difference can make it profitable for the incumbent monopolist to keep out entrants by pre-emptive innovation (Gilbert and Newbery, 1982), when the costs of innovation are sunk. But with network effects, the benefits of almost everyone being on the same system renders these markets prone to "tipping," giving a successful entrant the prospect of not sharing a duopoly but winning a monopoly. Investments that would both effectively deter entry and remain profitable to the incumbent may not be available when the competition is winnertake-all.

A second implication of network effects involves a fundamental logical flaw with conventional legal treatments of monopolization or abuse of dominance around the globe. That standard treatment requires demonstrating that a firm accused of abuse of dominance or monopolization possesses market power. Although that seems reasonable, it creates a

\footnotetext{
${ }^{12}$ The first copy of a major operating system might cost upwards of a billion dollars to produce; the cost of producing the second copy and any other is essentially zero.

${ }^{13}$ Much has been written about that case, including by me (Brennan 2001a, 2004a). My focus was that the US Department of Justice failed to bring the case it thought it was bringing, presenting largely evidence pertaining only to a mundane browser monopolization case and not to a largely unsupported strategic case involving future application platforms.
} 
paradox that one can illegally acquire market power only by having it in the first place (Brennan, 2007). With regard to Microsoft, it seems peculiar to argue that on the one hand, network effects, combined with application lock-in and scale economies, gave Microsoft vast market power, and then on the other hand argue that mere browsers are a threat. Cases such of this would be stronger if there were no barriers to entry other than the practice at issue; they would be more usefully construed as abuse creating dominance, not abuse of dominance (Brennan, 2007).

\section{$4 \quad$ Telecommunications}

We now turn to telecommunications. Our discussion begins first with the role of network effects in telephone policy and then turn to broadband Internet regulatory issues.

\subsection{Telephony}

Prior to the middle of the last century, the traffic delivery side of the telephone system possessed many of the features of a natural monopoly. At the long distance level, the high fixed cost of constructing terrestrial lines combined with relatively low traffic volumes precluded competition in that part of the industry. Technological change reduced cost and, to a lesser extent in the US thanks to regulation, prices. ${ }^{14}$ These factors, along with increased economic growth, led to increased volume. New technologies facilitated entry, as microwave radio transmission eliminated the need for expensive continuous rights of way between metropolitan areas.

The FCC, which grants licenses to use spectrum in the US, unintentionally allowed this entry, first by granting companies the right to provide internal communications over microwave frequencies in the late 1950s. Excess capacity led owners of these facilities to offer commercial private line service and then ordinary by-the-minute long distance service, following US Supreme Court decisions that put the burden of proof on the FCC to find that such services would not be in the public interest. AT\&T's resistance to entry in this market, and in telephone equipment markets where scale economies were never particularly credible, led to the antitrust case that led to AT\&T's divestiture of its local telephone exchange monopolies.

In what my students regard as ancient history, two factors made local telephone service a monopoly. A first was the physical scale economy in providing local telephone lines and networks; similar factors make water, electricity distribution, natural gas delivery, and other local infrastructure services monopolies. A second was network effects. These had little to do with the physical factors making local service and that had made long distance service a monopoly. Rather, these were driven by demand-side network externalities everyone wants to be able to reach everyone else - implying the efficiency of a single network.

\footnotetext{
${ }^{14}$ In Smith v. Illinois Bell Telephone Co., 282 US 133 (1930), the US Supreme Court required that some of the fixed costs of providing local service, notably the copper loop running to a customer's premises, be allocated to long distance and covered through those charges. As long distance costs fell, the allocation factor increased, in order to provide politically demanded subsidies for local telephone service. The subsidies created by this regime, paid within the then incumbent telephone monopoly in the US, AT\&T, encouraged entry into long distance as well.
} 
Technological change has brought about a transition in this local telecommunications infrastructure. In the US, most localities had two communications grids in place. In addition to the telephone exchange system, cable television networks had become widespread as a means of distributing multichannel video supported by direct viewer payment. Cable television systems initially were not capable of providing telephone service, as they were designed to deliver a single stream of content from a headend to all in the network. It was not set up for switched communication on demand between individual points. Cable networks could carry high-speed digital data, though, and the advent of this technology enabled the provision of telephony through voice-over-Internet-protocol (VoIP) service. At the same time, the switch to digital mobile telephony increased wireless capacity, making mobile service an increasingly attractive alternative to the incumbent landline telephone network.

Network effects remain. To deal with them in the US, the national legislature instructed the FCC to implement an interconnection regime so, at minimum, all carriers could deliver traffic to all other carriers. The interconnection policies in this legislation were designed to overcome the problem that an incumbent would rather retain its monopoly rather than facilitate entry. ${ }^{15}$ Because monopoly profits exceed those under competition, an entrant would have to have much lower costs than the incumbent to be able to still make money after compensating the incumbent for lost profits following the competition interconnection would bring. ${ }^{16}$ This is akin to a refusal of an incumbent monopolist to allow competitors to offer compatible products (Katz and Shapiro, 1994).

The regulatory problem does not end if competition is successful, however. The firms in a market still have to interconnect. If done outside the regulatory arena, it requires collective action. Even if this collective action is limited to interconnection, the firms still have an incentive to set the interconnection fee essentially equal to the monopoly markup (Brennan, 1997). The story is similar to one in which an industry agreed to adopt a standard, charged itself a fee to use that standard equal to the monopoly markup, and then divided the proceeds among themselves. Because of this possibility, regulators need to retain oversight over interconnection, not just to protect the ability of potential entrants to compete but to prevent the ability of a nominally competitive group of incumbents from effectively becoming a cartel.

\subsection{Internet}

The major technological change in telecommunications is the use of linked computers and digital communications devices sharing, using, and composing the vast packet network known as the Internet. It is impossible to do justice to the many ways in which the Internet has been a game-changer, but it has done so even with the confines of network-effect based regulation. One, alluded to above, is that by allowing content to be assembled and processed by the receiver, the network itself does not have to be adjusted based on the type

\footnotetext{
15 The US legislation constructed a complex regime to allow firms to offer local telephone service while using some or all of the facilities owned by the incumbent monopolist. Despite extensive regulatory and legal struggles over what the legislation mandated with regard to which network elements should be made available and at what price, local telephone competition in the US rests largely with carriers that do not share facilities. The ACCC continues to promote competition through use of shared facilities. ACCC, "ACCC proposes a five year extension for key telecommunications declarations,” News Release (6 May 2009).

${ }^{16}$ This cost advantage might not be necessary if the entrant was marginally more efficient and they could collude on price post-entry. In the other direction, an incumbent may be indifferent to interconnecting with an entrant if regulators hold it to zero profits regardless of what it does.
} 
of information transmitted. This may render spectrum use restrictions unnecessary. All a "television" needs is Internet access, and the user can find what she wants on whatever address the content provider uses. ${ }^{17}$

Of course, the Internet is itself a realization of network effects. It faces issues of standardization, governance, and interconnection that have affected telephony and other network infrastructures. The history of the Internet reveals another potential way in which network effects can change the way an industry works. A striking thing about the Internet is that while it has been exploited commercially, its origins, development, and structure are notable for the role of the public sector and private volunteer work. The technology for shared computer networks originated as a government funded defence research project in the US, to which universities were allowed to join. Many of those academics created and gave away the technologies that made the Internet what it is today, including the TCP/IP data networking protocol, the hypertext transfer protocol that created the World Wide Web, and the browser technology that allowed the Web to be easily used around the world.

As Microsoft, Cisco, and Google would attest, profit and the Internet are quite compatible. But the Internet is striking in the degree to which its success has rested on volunteer work, especially striking to an economist sceptical that volunteer work can accomplish much of anything. Volunteerism has worked here because of the combination of the ability for information to spread at low cost and network effects. An applicable network effect can make a great idea widely demanded. The low cost of information can make it easily shared, allowing it to cover a nation or the globe in a way that low-cost developments rarely do in typical businesses.

A prominent current regulatory policy debate, on net neutrality, is driven in part by this record of voluntarism that the Internet has uniquely sustained. Net neutrality is viewed as difficult to define, but the basic idea is that each provider of broadband services should treat equally all content deliver to customers (Hahn and Wallsten, 2006). ${ }^{18}$ This debate has been extensive, and a detailed description is beyond the scope of this paper. ${ }^{19}$ Arguments against regulation to ensure equal treatment are largely extensions of those against intervention in pricing generally. To the extent there is competition among broadband network providers, and in the US there is generally at least some, profit incentives should lead them to provide the speed and access consumers prefer. Even when competition is weak or lacking, a broadband provider still has an incentive to maximize the value of its service to its customers, presumably by maximizing access to content. With the growth in video and the demand to eliminate latency in transmission, some content providers will want to obtain and pay for higher costs priority guarantees in transmission. Audio and

\footnotetext{
17 The island country of Tuvalu has attempted to capitalize on this because it's assigned Internet domain is "tv", hence "owns" the right to use an Internet domain name ending in tv, as in "timbrennanguitar.tv", to pick a low-value example. Tuvalu, as an island nation no more than a few metres above sea level, is threatened by climate change, leading to among other things the question of what happens to an Internet domain disappears of the country to which it assigned disappears. Maney, Kevin, "Tuvalu’s sinking, but its domain is on solid ground," USA Today (27 Apr. 2004).

${ }^{18}$ Net neutrality, to my knowledge, does not entail requiring that all consumers be offered only one speed and quality level of Internet access.

19 A useful early survey of the issue is Ganley and Allgrove (2006). For a debate between a leading proponent and opponent, see Wu and Yoo (2007). Some economic arguments, primarily against regulations to ensure net neutrality, are summarized in Schwartz and Weiser (2009). For models of how discriminatory access to a network, see Economides and Tåg (2007) and Choi and Kim (2008). An op-ed setting out the case for net neutrality, by one of its leading advocates, is Lessig and McChesney (2006).
} 
video downloading can cause network congestion, making non-neutral traffic prioritization and management important and perhaps necessary (Glass, 2009).

Much of the argument in favour of net neutrality is driven by a general reluctance to believe that a monopolist or duopolist in broadband service will be interested in fairness or equality of access. The view of price discrimination among these advocates is no more favourable than it is outside industrial organization economists. Following the spirit of voluntarism, some of the arguments in favour of net neutrality are driven by the view that the small innovators who have done so much to create the Internet will be losers in a regime in which priority is based on ability to pay. Proponents of net neutrality have a couple of "horror stories" to which they can point, e.g., a Canadian provider blocking access to a union's website during a labour dispute. On the economic side, inability of a broadband monopolist to commit not to extract much of the value of innovations through ex post price discrimination may stifle ex ante incentives to innovate.

With the intensity of opinion on both sides, one wonders if there might be a middle position - and network effects may show the way. In traditional telephony, one of the arguments for policy intervention to ensure access on the consumer side, such as low "lifeline" rates was "universal service." Part of this was the network externality, that a telephone network is more valuable to each customer as more customers can be reached. A related motive was related more toward community values, e.g., being able to provide notice of emergencies. In meeting these universal service objectives, some minimum quality level of service was a given; they could not have been met by giving targeted households telegraphs or tin cans and strings.

Suppose that with the Web, a similar network effect creates a rationale for universal service with respect to content. The variation is not that everyone with content necessarily should get the right to make it available over the Internet. Rather, the content network effect arises because when someone makes content available, it routinely contains links to other content. The value of being able to make content available depends on the expected quality of those links. This may be particularly important if the links are to advertisers, whose payments support the website. If this matters, one has an argument for a cousin of net neutrality - not that all content be treated the same, but that all content be provided with a minimal level of service quality.

Whether such a rule can be sensibly implemented and, if so, whether the costs of such implementation are less than the benefits, I cannot answer. Reconciling minimum quality standards with user demand for continuous, virtual private-line connections over the Internet raises engineering feasibility and cost considerations beyond the scope of this paper. But it seems an idea worth considering, and not just as a compromise between two unforgiving positions.

\section{$5 \quad$ Electricity}

\subsection{Technological change effects on structure}

Electricity, certainly in the US, continues to be in a transition from regulation to partial competition that has lasted so long, and taken so many diverse routes, that "transition" may be a permanent state of affairs. The initial impetus in the US toward opening electricity markets was a combination of technology and politics (Brennan et. al., 1996). On the 
technological side was the development of relatively low cost natural gas generation. Costs were so low that when markets were initially opened to all potential generators in the US, the leading policy concern was whether regulators would have to compensate incumbents for "stranded costs," i.e., losses that they would have to bear because new entrants would be able to underprice them with such cheaply generated electricity.

The political impetus involved legislation to open electricity markets to qualifying nonutility generators - largely industrial cogenerators and early renewable fuel users - as a reaction to oil price shocks during the 1970s. The most important consequence of this policy was the realization that merchant generators could be feasibly connected to the transmission system and thus render the wholesale energy market competitive. Combined with a broader ideological commitment to deregulation, this led to legislation in 1992, implemented by the national electricity regulatory agency, the Federal Energy Regulatory Commission (FERC), which permitted independent generators to access the transmission grid.

FERC's authority covers only interstate wholesale bulk power markets, and even that is limited as states can effectively opt out of regional wholesale markets. Authority over whether end users can choose among electricity retailers also rests with state regulators. In the late 1990s, there was considerable enthusiasm to open retail markets to competition, spurred by extensive study and then implementation in California. Unfortunately, for a host of largely idiosyncratic reasons, the California electricity market imploded in late 2000, with huge run-ups in wholesale prices, distribution utility bankruptcies, rolling blackouts, and federal imposition of price ceilings in California's wholesale market (Brennan, 2001b). Since then, the movement to open retail electricity markets has been largely halted, with only Texas going forward and some states reversing course and going back to regulated retail rates.

So far, network effects have not figured into the story, other than as background standards, e.g., setting the alternating current cycle rates for long distance transmission, standardizing equipment voltage requirements, and instituting compatible plugs so equipment made or sold in a country can work everywhere within it. ${ }^{20}$ Network effects of interest arise because of physical limits to competition in all markets in the sector. Even where generation and retailing are potentially competitive, monopolies remain in the wires sectors of the business - local distribution and long distance transmission. Locally, the cause is familiar scale economies. A single grid going down the streets and into homes and businesses can carry all of the electricity those customers will use.

The argument is more complex for transmission. Because it is useful to have transmission lines interconnected to help move energy from regions in surplus to regions in deficit, electricity has and will take multiple paths to get from generators to retail loadserving entities. As a result of this phenomenon, known as parallel or loop flow, if one entity increases its transmission capacity, the costs to others of offering transmission service fall. An interconnected transmission system is a single entity, even if different utilities own different pieces of the grid. ${ }^{21}$

\footnotetext{
${ }^{20}$ Similar compatibility issues may arise in designing appliances to communicate over different "smart grid” systems that allow remote management of energy use, especially to limit use during peak demand periods.

${ }^{21}$ This network effect may not be as relevant in other countries, such as Australia, as for the US. In the US, population density over a two-dimensional geographic area gives transmission the topology of a grid with multiple routes between points. Australia, with most of its population lying on a line close to the eastern and
} 
As a consequence, network effects arising from non-pecuniary horizontal externalities come into play. This network aspect of electricity creates two very difficult problems for electricity regulators. The first is whether efficiency grid management is sustainable with vertical separation between generation and transmission thought necessary to promote competition in the former. The second is how to ensure that the overall grid remains reliable while individual participants compete.

\subsection{Vertical separation vs. coordination}

Central to FERC's regulatory orders to implement electricity competition was a recognition that control over the transmission grid needed to be separated from ownership of generation that would use it. FERC addressed this not once but twice, setting up rules for instituting “Independent System Operators” in 1996 when first developing transmission open access policies, refined with a change of name of these organizations to "Regional Transmission Organizations” (RTOs) in 1999. Canadian provinces that have opened up their grids to competition have instituted similar arrangements (Brennan, 2008c).

Although these policies do not go as far as the full divestiture imposed when the then telecommunication monopoly AT\&T was broken up in 1984, the rationales are similar (Brennan, 1987). The primary justification is to discourage evasion of regulation through discrimination against competitors in the quality, timeliness, or availability of access to the regulated facility. Discrimination creates an artificial advantage in the competitive market, in effect tying the competitive service to the regulated service. This allows a vertically integrated firm to obtain the profit over its monopoly that regulation was intended to preclude. The other justification for separation it to prevent cross-subsidization, here defined as misallocating costs of the competitive service to the regulated side's books. If a vertically integrated firm could get away with this, it would be able to raise rates for the regulated service closer to the monopoly level and possibly make credible predatory pricing threats in the competitive market. ${ }^{22}$

The vertical separation FERC instituted for US bulk power markets is functional, not corporate. Utilities can own both generation and transmission, but the operation of the latter is vested in a nominally independent board. The challenge for regulators is whether even this moderate separation of the regulated network part of the industry from the competitive part is beneficial on net. The specific question is whether the competitive and regulated sides of the industry can go about their business without the need to coordinate. This has two aspects, short-run operation and long-run investment, and both are illuminated by comparing them with similar issues in telecommunications (Brennan, 2006).

With regard to short-run operations, in telecommunications it was relatively easy for regulators to set the access prices local exchanges could charge long distance carriers to originate and terminate calls, and it was relatively easy for long distance carriers to operate in their market taking that price as given. ${ }^{23}$ The competitive and regulated sectors could

southeast coasts, may not have the same degree of parallel transmission responsible for this loop flow network effect.

${ }^{22}$ Regulation plays a crucial role in both these arguments. If regulation is not present, the vertically integrated firm can exploit its market power directly and does not need to vertically integrate to do so through either discrimination or cross-subsidization.

23 Access charges for network elements following opening of local markets to entry under the 1996 Telecommunications Act was much more contentious (Brennan, 1999). 
operate independently, and prices could be designed to cover infrastructure costs. In electricity, by contrast, access prices to the transmission grid need to be set on a node-bynode, time-varying manner to provide the right signals to generators to avoid trying to inject energy onto congested lines (Hogan, 1992). Time-varying prices require constant adjustments to ensure that excess profits do not fall onto those who own the grid or "congestion rights" used to hedge against variation in transmission charges (Joskow and Tirole, 2000). The desirability of having these prices vary over time adds a layer of complexity to the process needed to set access in telecommunications, where highly time and location sensitive congestion was not a strong consideration. ${ }^{24}$

An even more consequential challenge with separation involves long-term investment in this infrastructure (Van Doren and Taylor, 2004). Unlike telecommunications, expansion of generation and transmission both typically involve expensive, large-scale investments that are worthless unless the other is in place. The resulting need to coordinate may foreclose the ability of entrepreneurs to make investment and expansion decisions independently, based on private knowledge of the market, without having to share that knowledge with rivals. This problem will be more crucial with climate change, where massive investments in wind and solar generation, and transmission lines to carry that energy to population centres, will be required. ${ }^{25}$

\subsection{Reliability vs. competition}

Outside of using electricity to raise water levels in hydroelectric dam reservoirs so energy can be generated later, electricity once generated is cannot be stored. Thus, the quantity of electricity generated and the quantity of electricity used have to be kept equal on virtually a minute-by-minute basis. Too much electricity produced can overheat transmission systems; too little can lead to blackouts. Markets normally can deal with this by offering customers different levels of reliability at different prices. But because of network effects arising from interconnected transmission, blackouts because one supplier fails to meet its customers' demands are not restricted to those customers; it spreads across the grid as a whole. This makes reliability a public good in the economist's sense, not just as something in the public interest.

Ex post liability for causing blackouts is probably not feasible. Assigning responsibility in an interconnected network is likely to be problematic, especially in the context of damage litigation. So too will be estimating the costs of a blackout. Finally, if those costs are substantial, a losing defendant may be judgement-proof if it can avoid liability by exiting through bankruptcy. Managing reliability problems for this infrastructure thus becomes a matter for ex ante regulation.

This creates challenges of both implementation and foundation. At the implementation level, the standard method for preventing blackouts is to require that generators or load serving entities have access to reserve capacity which they can bring online to meet unexpected surges in demand or compensate for unanticipated generators breakdowns. Meeting these requirements has led to the design, institution, and analysis of "capacity markets," apart from the markets in energy itself - a feature unique to electricity (Cramton and Stoft, 2005). Among the questions to be answered is the definition of capacity, the

\footnotetext{
${ }^{24}$ As the Internet becomes a greater source for high volume content, e.g., high-definition video, congestion pricing may well become more important, as pointed out in the above discussion of net neutrality.

${ }^{25}$ A referee points out that these problems can plague rail, where large-scale coordinated investments must be made when service is to be expanded.
} 
price a transmission operator or other entity will pay for that capacity when it is invoked, and how the reserve requirements underlying that capacity are instituted. Inadequate attention has been paid to how those requirements translate into the energy-only prices paid by end users (Brennan, 2003a). One possibility is that the benefit of the requirements is not the capacity itself but, if imposed on the basis of peak-period use, in internalising the negative externality that one's marginal electricity use increases the likelihood of a blackout borne by all (Brennan, 2008b). ${ }^{26}$

As with the vertical separation argument, the larger question is whether competition is compatible with central control. Here, the issue is not coordination of short-term supply or long-term investment, but whether the grid can be operated at all without central authority over dispatch. ${ }^{27}$ After nearly fifteen years of looking at this sector, I remain agnostic as to whether the scope of central authority necessary to ensure supply of reliability as a public good is compatible with competition. The scope may be no greater than that of having air traffic controllers oversee flights among competing air carriers. Fortunately, the US has seen only one major region-wide blackout since the California meltdown. Whether this indicates luck or that wholesale markets work remains an open question.

\section{$6 \quad$ Finance}

Along with the extensive and serious problems the recent global financial crisis has created for the public, business, and policymakers, it surely has made more difficult the process of raising capital for infrastructure maintenance and expansion. Recession-driven reductions in demand also likely introduce explicit impediments to ensuring that ex post revenues meet ex ante profit commitments or expectations. Those involved with the day-to-day operations and on-the-ground planning and regulation of these infrastructure enterprises rail and water as well as telecommunications and electricity - can speak to the specific problems presented by the global financial crisis.

The global financial crisis also illuminates the issues presented regarding telecommunications and electricity, in the way considering broadcasting, standard-setting, and computer software does - in adding to our understanding of network effects. Other than a couple of bumps, finance markets have operated with sufficient smoothness to be off the radar screen of all but the specialists. To the extent they have been the objects of regulatory policy in the US in the last few decades, it has largely been to seek and implement opportunities to reduce or eliminate regulatory restrictions of interest rates, branch locations, and lines of business.

Neglected in all of this is the fundamental nature that the global financial system is a network, not just as a metaphor for a large and crucial infrastructure. The financial system, at its apex, is subject to network effects as are telecommunications and electricity. The interconnected aspect of the financial system - large banks, insurers, investment houses

\footnotetext{
${ }^{26}$ Negative blackout externalities also rationalize policies to subsidize or mandate real-time pricing, to enable consumers to see and react to the high costs of providing peak power. Because capacity needs to be in place to meet peak demand, which may be realized only a few hours out of the year, the price of electricity over those few hours necessary to cover those costs can be 50-100 times normal cost (Brennan, 2004b).

${ }^{27}$ Perhaps indicating a broad role for the central grid operator, David Swift of the Australian Energy Market Operator said during his talk at the ACCC conference mentioned in the opening footnote that "dispatching the right unit at the right time is crucial."
} 
and hedge funds lending to and borrowing from each other - implies that participants create and are subject to horizontal non-pecuniary externalities. In that regard, the financial system resembles the electricity grid, in which one competitor's failure can impose costs on or bring down its rivals.

The cause of network effects in financial markets is not a function of physical imbalances of demand and supply, as in electricity, but of asymmetric information, specifically adverse selection. Adverse selection is inevitable in lending markets, as those with private information on the likelihood of default are more likely to borrow. Consequently, little borrowing of significance matches the dictionary definition; what we call "borrowing" is the temporary transformation of illiquid assets - collateral - to liquid funds. Without collateral to provide a reasonable assurance of payback, whether borrowing against a car, house, business, or commercial assets, major borrowing would cease.

Normally, lending among investment banks covers short-term deficit positions - not unlike energy trading among interconnected electricity suppliers. With little uncertainty, this market works smoothly and invisibly as far as the "real" non-financial economy is concerned. But when some of these borrowers may be holders of so-called "toxic assets,"28 the confidence in the ability of any potential borrower to pay back the loans comes into question. This credit market falls victim to adverse selection, and as George Akerlof famously pointed out when introducing the concept in economics, such a market can disappear (Akerlof, 1970). At best, borrowers most likely to default could obtain funds at sky-high rates reflecting that default probability. At worst, the market could simply vanish almost overnight; it was this rapid vanishing that provides the best evidence that adverse selection was the root of the credit market meltdown.

The potential for adverse selection creates the network effect. The risk that my credit could be bad creates a perception that yours might be as well. As with other networks, a policy response may be warranted to mitigate the potential negative externalities associated with a contagious breakdown of a network. One would be better information to reduce the asymmetry between borrowers and lenders that creates the potential for adverse selection. This may entail rules requiring that credit rating services not be the paid agents of the financial instruments they wish to regulate. A less intuitively appealing but understandable response could be to limit the scope of financial instruments, e.g., prohibit sufficiently complex derivatives, to reduce the burden on investors of ascertaining their underlying expected value and risk. Another set of remedies involves the government stepping in to provide collateral, such as deposit insurance. An extreme version of this would be for the government to cover losses of these financial institutions - the "bail out," as it is called in the US. But this may replace the risk of adverse selection with a risk of moral hazard, as lenders become less cautious knowing they will be rescued.

Most germane here is that responses to the global financial crisis involve proposed regulations of the sort we have been talking about for the network infrastructures of telecommunications and electricity. A relevant notion from both sectors is to restore the idea of separating regulated from unregulated sectors. Here the justification is not to preserving competition but mitigating moral hazard created if the government, in providing

\footnotetext{
${ }^{28}$ In the US, the major toxic assets were derivatives of bundled home mortgages, many of which had been obtained at low interest rates and without significant credit checks. These derivatives lost value or became worthless when housing prices began to fall a couple of years ago. For purposes of this discussion, we do not need to attempt to look into the factors that led to the creation of these assets and the underlying causes of their toxicity.
} 
deposit insurance for some types of accounts, ends up having to bail out institutions that expand into more risky areas.

A second idea comes from looking at electricity. Just as electricity networks become vulnerable when individual suppliers run too close to the edge of where demand could exceed capacity, so too may credit markets become vulnerable when lenders get too close to the edge of where assets could fail to cover liabilities. This is the rationale for reserve requirements for banks and, following the global financial crises, to extend those requirements to investment houses and other financial institutions that participate in this interconnected market for large scale, short-term credit.

Part of the analogy is to pay close attention to cost and benefit comparisons. For electricity, the cost of adding generation capacity to meet a particular reserve target should be related to the expected cost of a blackout. Applying that model to the financial sector similarly requires that one balance the benefits of reduced likelihood and severity of recessions against the costs of regulations that in normal times reduce the ability to hedge and manage risk. One could ask, using purely illustrative numbers, if a risk of a $6 \%$ reduction in economic activity every thirty years is worth a reduced rate of growth of .5\% per year for those years resulting from less unencumbered, agile and innovative capital management.

\section{$7 \quad$ Lessons}

Technological change, policy transitions, and the fact of regulation itself from either the price side or the competition side, are intimately connected with network effects in infrastructure industries. While the concept seems simple, it has multiple definitions and drivers, including demand-side preferences for using a common technology, supply-side compatibility interests, and more broadly, horizontal non-pecuniary externalities. This review of the role network effects play in sectors covered by traditional regulators, others may regulate, or sit outside regulation, shows that the response to network externalities is varied and complex across all conceivable dimensions of causes, targets, rationales, and governance. These complexities go beyond the initial interest in whether coordination failures lead to less beneficial standards or whether market forces can and do overcome them.

We began by looking first at some sectors outside the usual list of regulated sectors. Broadcasting shows that the term "network" may have little do with network effects, but also shows the value and difficulty of setting regulatory standards to foster compatibility among transmitters and receivers. Private standard setting is a response to network externalities, and has engendered concern across competition agencies, some of it in my view misplaced. One potentially interesting application of network effects in competitive sectors was the Microsoft case, but that setting illustrated that network effects may limit the likelihood of competitive harm of strategic conduct. Network effects constitute an independent entry barrier rendering strategic conduct less necessary, and because the make the market prone to tipping, they reduce asymmetries between incumbents and entrants that can make entry deterrence both profitable and effective.

The complexity of network effects in practice is compounded when we turn to the traditionally regulated sectors of telecommunications and electricity. In telecommunications, network effects complemented physical scale economies, arising in 
the interest of customers in being able to call each other. As technological changes fortuitously led to competitive alternatives on the physical side, policy interests in maintaining network benefits through efficient interconnection regimes have become paramount, with a regulatory role continuing even as the industries transitions from monopoly to competition.

A second set of telecommunications network effect issues has arisen in connection with the Internet. By relying on intelligent data processing at the user end, the Internet may reduce or eliminate the need for private or public rules to ensure compatibility of specialized equipment, such as televisions. The Internet also shows how network effects have made public and volunteer contributions to standards and designs crucial. This legacy has led to concerns about "net neutrality." A potential resolution of the "net neutrality" debate, minimum standards rather than equal treatment, itself arises from network effects, applying to web content providers the customer-based "universal service” network externality rationale for subsidizing telephone penetration.

Turning to electricity reveals yet another network effect, arising because the transmission is in effect a shared system. If one electricity supplier fails to meet the demand of its customers, a blackout can spread across the entire grid. This network effect sheds some light on the difficulty and perhaps feasibility of transitions to competition in infrastructure sectors. One is that vertical separation necessary to promote competition can be difficult if prices and investment cannot be implemented without coordination with residual monopolies; the positive record in telecommunications may not be exportable to electricity. A second is that network effects making reliability a public good set up a conflict between central planning and independent entrepreneurship that could - not necessarily will - thwart efforts to introduce competition.

Before concluding, two other lessons merit brief mentions. A first is the possible need for international regulatory coordination. When the geographic scope of network effects rests within national boundaries or sub-national regions, the appropriate governance structure will be national or sub-national as well (Brennan, 2003b, 2003c). ${ }^{29}$ However, in some cases the network effects may go across national boundaries. In North America, much of the electricity grid is common to the US and Canada, and blackouts in one have spread to the other. Other contexts where network effects are international include telecommunications numbering plans, Internet protocols, and as has been made very clear in the recent global financial crisis, in financial markets. International governance, while appropriate, raises political, protectionist and economic complexities beyond the scope of this paper. ${ }^{30}$

The last point is that as infrastructure industries transition in whole or in part to competition, so too may policy oversight transition from sector-specific regulation to general competition law. As this latter transition plays out, the question of which takes precedence takes on special importance. US history is particularly problematic in this area. Twenty-five years ago, when US antitrust enforcement led to the break-up of the telephone monopoly, the prevailing legal rule was that competition law took precedence unless there was a "plain repugnancy" between it and the underlying regulatory scheme. ${ }^{31}$

\footnotetext{
${ }^{29}$ This principle also holds for competition enforcement (Brennan, (1984).

30 As the owner of a US mobile phone that works nowhere else in the world, I am well aware that international governance could be more authoritative.

${ }^{31}$ MCI v. AT\&T, 708 F.2d 1081, 1102 (7th Circ., 1983).
} 
In the last five years, the US Supreme Court, with the support of the US competition agencies, has reversed this position, finding that if a sector-specific regulatory has authority over rules affecting competition, the costs of additional antitrust enforcement exceed benefits. ${ }^{32}$ Although scepticism regarding policies to require firms to deal with rivals is warranted, the recent reversal in the US undercuts the principle underlying vertical separation to protect competition in sectors with competitive markets connected to regulated monopolies.

\section{$8 \quad$ References}

Akerlof, G. (1970) “The Market for 'Lemons': Quality Uncertainty and the Market Mechanism,” Quarterly Journal of Economics, 84: 488-500.

Arthur, W.B. (1994) Increasing Returns and Path Dependence in the Economy. University of Michigan Press: Ann Arbor.

Australian Competition and Consumer Commission (2009) "Tenth ACCC Regulatory Conference: The regulation of infrastructure in a time of transition" http://www.accc.gov.au/content/item.phtml?itemId=866434\&nodeId=725309e7dcf592 3afc15992689d0d5ea.

Brennan, T. (1984) "Local Government Action and Antitrust Policy: An Economic Analysis,” Fordham Urban Law Journal, 12: 405-36.

Brennan, T. (1987) "Why Regulated Firms Should Be Kept Out Of Unregulated Markets: Understanding the Divestiture in U.S. v. AT\&T,” Antitrust Bulletin, 32: 741-93.

Brennan, T. (1997) "Industry Parallel Interconnection Agreements," Information Economics and Policy, 9: 133-149.

Brennan, T. (1998) “The Spectrum as the Commons: Today's Vision, Not Tomorrow's Prescription,” Journal of Law and Economics, 41: 791-803.

Brennan, T. (1999) "Comparing 'Stranded Costs' Arguments in Telecommunications and Electricity,” in M. Crew (ed.) Regulation Under Increasing Competition. Kluwer Academic Press: Norwell, MA.

Brennan, T. (2001a) "Do Easy Cases Make Bad Law? Antitrust Innovation or Missed Opportunities in U.S. v. Microsoft," George Washington Law Review, 69: 1042-1102.

Brennan, T. (2001b) The California Electricity Experience, 2000-2001: Education or Diversion? Resources for the Future: Washington.

Brennan, T. (2003a) “Electricity Capacity Requirements: Who Pays?” Electricity Journal, 16(8): 11-22.

\footnotetext{
${ }^{32}$ Verizon v. Trinko, 540 U.S. 398 (2004); for a critical assessment, see Brennan (2005).
} 
Brennan, T. (2003b) "Provincial and Federal Roles in Facilitating Retail Electricity Competition," in W.D. Walls (ed.) Regional Transmission Organizations: Restructuring Electricity Transmission in Canada. Van Horne Institute: Calgary.

Brennan, T. (2003c) "The FCC and Policy Federalism: Broadband Internet Access Regulation," in G. Madden and S. Savage (eds.) International Handbook of Telecommunications Economics, Volume III. Edward Elgar: Northampton, MA.

Brennan, T. (2004a) “The Legacy of U.S. v. Microsoft,” Regulation, 26(4): 22-28.

Brennan, T. (2004b) "Market Failures in Real-Time Metering," Journal of Regulatory Economics, 26: 119-39.

Brennan, T, (2005) “Trinko v. Baxter: The Demise of U.S. v. AT\&T,” Antitrust Bulletin, 50: 635-64.

Brennan, T. (2006) "Alleged Transmission Inadequacy: Is Restructuring the Cure or the Cause?” Electricity Journal, 19(4): 42-51.

Brennan, T. (2007) “Saving Section 2: Reframing U.S. Monopolization Law," in V. Ghosal and J. Stennek (eds.) The Political Economy of Antitrust. North-Holland: Amsterdam.

Brennan, T. (2008a) "Bundled Rebates as Exclusion rather Than Predation," Journal of Competition Law and Economics, 4: 335-374.

Brennan, T. (2008b) "Is the Benefit of Reserve Requirements in the 'Reserve' or the 'Requirement'?” Resources for the Future Discussion Paper 08-33 http://www.rff.org/RFF/Documents/RFF-DP-08-33.pdf.

Brennan, T. (2008c) Generating the Benefits of Competition: Challenges and Opportunities in Opening Electricity Markets, Commentary 260, C. D. Howe Institute: Toronto.

Brennan, T. (2009) "The challenges of climate for energy markets," Resources for the Future Discussion Paper 09-32 http://www.rff.org/RFF/Documents/RFF-DP-0932.pdf.

Brennan, T. et. al. (1996) A Shock to the System: Restructuring America's Electricity Industry. Resources for the Future: Washington.

Choi, J.P. and B.-C. Kim (2008) “Net Neutrality and Investment Incentives,” CESifo Working Paper Series Number 2390 http://ssrn.com/abstract=1264934.

Cramton, P. and S. Stoft (2005) “A Capacity Market that Makes Sense,” Electricity Journal, 18(7): 43-54.

David, P. (1985) “Clio and the Economics of QWERTY,” American Economic Association Papers and Proceedings, 75: 332-337. 
Doganoglu, T. and J. Wright (2010) "Exclusive Dealing with Network Effects," International Journal of Industrial Organization (forthcoming,) http://profile.nus.edu.sg/fass/ecsjkdw/EXCNET_270309.pdf).

Economides, N. and J. Tåg (2007) "Net Neutrality on the Internet: A Two-Sided Market Analysis," NET Institute Working Paper Number. 07-45 http://ssrn.com/abstract $=1019121$

Farrell, J. and G. Saloner (1985) "Standardization, Compatibility, and Innovation,” RAND Journal of Economics, 16: 70-83.

Froeb, L. and B. Ganglmair (2009) "An Equilibrium Analysis of Antitrust as a Solution to the Problem of Patent Hold-Up," Vanderbilt Law and Economics Research Paper 0911 http://ssrn.com/abstract=1340722.

Ganley, P. and B. Allgrove (2006) "Net Neutrality: A User's Guide,” Computer, Law \& Security Report, 22: 454-63.

Gilbert, R. and D. Newbery (1982) "Pre-emptive Patenting and the Persistence of Monopoly,” American Economic Review, 72: 514-526.

Glass, V. (2009) “Service Quality: Where Switches and Packets Meet,” Rutgers University Center for Research in Regulated Industries, Advanced Workshop in Regulation and Competition, 22 ${ }^{\text {nd }}$ Annual Western Conference, Monterey, CA. June 17.

Hahn, R. and S. Wallsten (2006) “The Economics of Net Neutrality,” Economists Voice, (June): 1-7.

Hogan, W. (1992) “Contract Networks for Electric Power Transmission,” Journal of Regulatory Economics, 4: 211-42.

Joskow, P. and J. Tirole (2000) "Transmission Rights and Market Power on Electric Power Networks,” RAND Journal of Economics, 31: 450-48.

Katz, M. and C. Shapiro (1985) "Network Externalities, Competition, and Compatibility,” American Economic Review, 75: 424-440.

Katz, M. and C. Shapiro (1986) "Technology Adoption in the Presence of Network Externalities,” Journal of Political Economy, 94: 822-841.

Katz, M. and C. Shapiro (1994) “Systems Competition and Network Effects," Journal of Economic Perspectives, 8(2): 93-115.

Lessig, L. and R. W. McChesney (2006), "No Tolls on the Internet," Washington Post (June 8): A23.

Liebowitz, S. and S. Margolis (1990) "Fable of the Keys," Journal of Law and Economics, 33: 1-25. 
Liebowitz, S. and S. Margolis (1994) "Network Externality: An Uncommon Tragedy," Journal of Economic Perspectives, 8(2): 133-150.

Liebowitz, S. and S. Margolis (1995) "Path dependence, lock-in and history," Journal of Law, Economics, and Organization 11: 205-226

Liebowitz, S. and S. Margolis (1996) "Should Technology Choice be a Concern for Antitrust?” Harvard Journal of Law and Technology, 9(2): 283-318.

Rasmusen, E., M. Ramseyer and J. Wiley (1991) “Naked Exclusion,” American Economic Review, 81(5): 1137-45.

Schwartz, M. and P. Weiser (2009) "Introduction to a Special Issue on Network Neutrality,” Review of Network Economics, 8: 1-12.

Sidak, J.G. (2009) "Patent Holdup and Oligopsonistic Collusion in Standard Setting Organizations,” Journal of Competition Law \& Economics, 5: 123-88

Taylor, J. and P. van Doren (2004) "Rethinking Electricity Restructuring," Cato Institute Policy Analysis Number 530.

Vanberg, Margit (2005) “Network Externalities and Interconnection Incentives,” ZEW Centre for European Economic Research Discussion Paper Number 05-080 http://ssrn.com/abstract=862124.

Wright, J., (2009) "Why the Supreme Court Was Correct to Deny Certiorari in FTC v. Rambus," George Mason Law \& Economics Research Paper Number 09-14 http://ssrn.com/abstract=1349969.

Wu, T. and C. Yoo (2007) "Keeping the Internet Neutral?” Tim Wu and Christopher Yoo Debate,” Federal Communications Law Journal 59(3): 575-92. 